\title{
The Effects of Intravenous Antibiotic Administration during the Surgical Removal of Third Molar: Systematic Review
}

\author{
Ramasamy Chidambaram* \\ Department of Prosthodontics, Faculty of Dentistry, AIMST University, Jalan Bedong-Semeling, Bedong, Kedah Darul Aman, MALAYSIA.
}

\begin{abstract}
Intravenous antibiotics a subset of parenteral route help in reducing the post-operative infections in dento-alveolar surgery such as the removal of third molar. However, this route lacks evidential support in the literature and thus has received less attention among the oral clinicians and proportionally in pharmacologists. A systematic review was performed in the Pubmed, Pubmed Central and Scopus electronic data bases from January 2003- January 2017 with a view to express the last fifteen years performance. From the primary queries, only 74 references could be collected pertinent to antibiotic therapy in third molar surgery including the protocols laid by American Association of Oral maxillofacial Surgeons and American Academic of Pediatric Dentistry. In the final stage, a couple of articles on in vitro studies, three short discussions, one evidence-based report and a letter to editor met the required desired criteria. The results revealed that it is highly preferable to administrate intravenous antibiotics in high-risk individuals to reduce surgical site infections. From the retrieved evidences,
\end{abstract}

it can be asserted that candidates with clinical signs of rapid progressive infection, total osseous impaction and compromised health deserve to receive a pre-operative single dose of intravenous antibiotics during third molar surgery on the grounds of their vulnerability to bacteremia.

Key words: Antibiotics, Bacteremia, Intravenous, Oral Surgery, Impacted, Third Molar.

Correspondence

Dr. Ramasamy Chidambaram,

Senior Lecturer, Department of Prosthodontics, Faculty of Dentistry, AIMST University, Jalan Bedong- Semeling- 08100 Bedong, Kedah Darul Aman, MALAYSIA.

Phone: +60 164724370

Email:dr.ramasamyc@gmail.com

DOI: 10.5530/jyp.2019.11.49

\section{INTRODUCTION}

Oral surgery, Endodontics and Periodontics are among the major dental disciplines that use antibiotics at most to treat oral infections. Dental extraction, a traditional procedure performed in dental practice, does not require antibiotics for healthy individuals. Due to the high chances of bleeding during dento-alveolar surgery, dental practitioners prescribe antibiotic prophylaxis. ${ }^{1}$ Oral route is the standard method of delivering antibiotics in a routine practice. In few occasions, the compromised health of a patient coupled with severe infection requires to choose parenteral route. Intravenous antibiotics (IV), a subset of parenteral route, help in reducing the post-operative infections in dento-alveolar surgery such as the removal of third molar. However, this route lacks evidential support in the literature and thus has received less attention among the oral clinicians and proportionally in pharmacologists. Is there any association between intravenous antibiotics and dento-alveolar surgery? The present communication is the first one of its kind that aims to answer this question by collecting scientific evidence from the available literature.

\section{MATERIALS AND METHODS}

\section{Search terms}

A systematic review was performed in the Pubmed, Pubmed Central and Scopus electronic data bases using the following terms "antibiotic prophylaxis", "bacteremia", "third molar", "impacted tooth", "intravenous administration", "infection", "postoperative complication", "oral surgery"

\section{Design}

The main aim of the literature search was focused on finding the cases when intravenous antibiotics were applied during third molar surgery. This search query did not yield enough positive results in line with the ti- tle. Therefore, the articles concerned with antibiotic prophylaxis in dental practice were explored to meet the target query. The range of criteria was restricted to systematic reviews, studies incorporating retrospective or prospective aspects and randomized clinical trials. Special remarks of researchers, generic data from private websites and organizations and animal studies were excluded to provide authentic information on intravenous antibiotic influence during third molar surgery in humans. The entire audit was limited to manuscripts written only in English language and published during January 2003- January 2017, with a view to express the last fifteen years performance.

\section{RESULTS}

From the primary queries, only 74 references could be collected pertinent to antibiotic therapy in third molar surgery including the protocols laid by American Association of Oral Maxillofacial Surgeons (AAOMS) (Clinical practice guidelines for oral and maxillofacial surgery; Summary of third molar clinical trials) and American Academic of Pediatric Dentistry (AAPD) (Guideline on antibiotic prophylaxis for dental patients at risk of infection). In the final stage, only seven titles remained worth consideration that discussed significance of antibiotics during third molar surgery in an unclear way except one evidence-based report that projected the potential benefits of intravenous route and a letter to editor that addressed the indications of IV antibiotics (Figure 1). We could not find even a single exclusive review on IV antibiotics. Regarding randomized clinical trials, there were six prospective studies citing parenteral antibiotic application. Among them, only two clinical reports adopted intravenous administration while the remaining four adopted intramuscular administration and thus were eliminated. Finally, a couple of articles on 
in vitro studies, three short discussions, one evidence-based report and a letter to editor met the required desired criteria (Table 1).

\section{DISCUSSION}

Intravenous therapy is an optimum route mostly preferred for the treatment of hospitalized patients. Dental practitioners, who mostly encounter only outpatients, get very few opportunities to take advantage of IV antibiotics. In cases when an individual shows discomfort or difficulty in deglutition, such alternative (IV) routes certainly help the oral clinicians, but this potential route has its own positive and negative effects. ${ }^{2}$ The apprehension of contraindications not reported so far discourages the dental clinicians to use IV antibiotics. Meanwhile, the upcoming discourse compiles the indications, contraindications, advantages and setbacks to have a better understanding of IV antibiotics.

Injection and infusion are the available modes of delivering parenteral antibiotics. The former one includes intravenous, intramuscular (IM) and subcutaneous (SC) modes. In justification to the title of this article, we are considering only IV antibiotics that aid dental professionals during third molar surgery. Oral-maxillofacial surgeons are the key players involved in dento-alveolar surgery. The removal of third molar, a subset of dento-alveolar surgery, is one of the common surgical procedures performed by oral surgeons. ${ }^{3}$ In contrast to the major surgical procedures; these are performed in a dental unit under local anesthesia, which has attracted a large population of general dentists. Theoretically, the third molar surgery is classified under the 'Clean Wounds', which do not require antibiotic prophylaxis owing to its low possibility of microbial contamination. Meanwhile, dental literature also indicates that third molars are the most commonly impacted teeth associated with pathologies such as dental caries, periodontitis, bone resorption, cyst and tumor, which might also carry subsequent infections. ${ }^{4-9}$ The worldwide statistics indicate the prevalence of impacted third molars as $24.40 \%$ with an increased preference in mandibles and mesio-angular impaction as the commonest. ${ }^{10}$ In the context of American experience, the reports state that around ten million teeth are removed each year owing to associated risks. ${ }^{11} \mathrm{~A}$ retrospective report of Indian scenario mentions that from the total sample of 700 candidates, $34.1 \%$ had minimum of one impacted third molar. ${ }^{12}$ The stated information justifies that the third molar tooth is a major concern to the oral physicians and patients on the grounds of as-

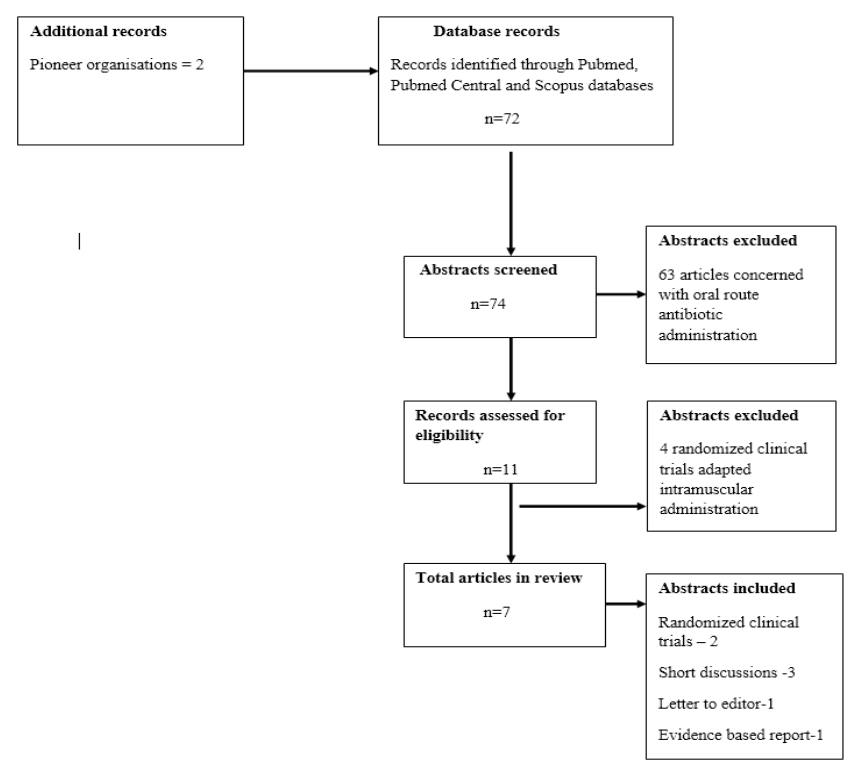

Figure 1: Flow chart of study selection. sociated complications and infections. Besides this, there are also certain pre-disposing risk factors such as smoking, old age, anatomy of tooth, periodontitis, radiotherapy and poor oral hygiene, which make the patient more vulnerable to infections. In order to control the progressive infection and prevent complications oral clinicians administer antibiotic via systemic or local route. ${ }^{13}$ The overall post-operative infection rate is $0.8-4.2 \%$ during the third molar surgery and considering the potential risk towards bacteremia, the medically complex patients require the support of parenteral antibiotics. ${ }^{14}$ At the same time, the requirement should be conservative in high-risk patients especially in those implanted with medical devices such as shunts, catheters, prosthetic joints and penile or breast prosthesis. ${ }^{15-19}$ The existing systemic conditions (chronic kidney or liver disease, malnutrition, etc.) could also affect wound healing and delay the recovery. ${ }^{20-23} \mathrm{As}$ a precautionary measure, it is a wise advice from medical experts to be prepared for any dental emergency for such a special category of patients. ${ }^{24-26}$

On the other hand, other group of experts suggests retaining the asymptomatic tooth on the request of patients. This raises a concern over conserving an impacted tooth? As in such circumstances, the undertaken clinical trials, reviews, surveys regarding the impacted third molar might result in a wrong conception. However, few scholars strongly recommend surgical practice for the patients with evident pain and correlated bone pathologies. ${ }^{27-29}$ Nevertheless; the prospective studies are still inadequate to support the prophylactic removal of third molar. In conclusion, from a patient's standpoint, the retention of third molar tooth should surpass the potential risk factors in order to sustain the general health. However, when a medically complex candidate with restricted oral access seeks third molar surgery, administration of IV antibiotic benefits the surgical procedure, which can be better justified with the supporting literature. In the oral surgery discipline, very few studies have been undertaken to assess the impact of IV antibiotics during dento-alveolar (third molar) surgery. An earlier prospective report documented by Foe and his team mentions the administration of ampicillin (1g IV $\backslash 1$ hr pre-op) to improve clinical recovery of patients. ${ }^{30}$ Penicillin and its derivatives (ampicillin) has been an asset to the healthcare professionals since their discovery and by the virtue of the protection against infections caused by anaerobic bacteria. A similar study by Halperan et al. also supports the earlier evidences. A comparison between the penicillin $(15,000$ units/kg IV) \Clindamycin (300 mg IV, CG: 0.9\% saline solution) and placebo groups (CG: $0.9 \%$ saline solution) was carried out in a sample of 118 patients to determine the incidence of surgical infections after removal of third molar. ${ }^{31}$ The candidates in the former group had no sign of infection or any complication, while those in the later group showed an infection rate of $8.5 \%$. Candidates with penicillin allergy were given clindamycin, (300 mg IV) which naturally possess excellent tissue penetration and thus carry the post-antibiotic effect in bloodstream. ${ }^{32}$ The other interesting principle laid down in earlier studies was dosage timing. The authors claimed that a single dose of IV antibiotics administered one hour preceding the incision is adequate..$^{30,31}$ With sufficient blood levels of the antibiotic and a proper timing, the colonization of bacteria can successfully be prevented. The longer a drug stays in bloodstream; the better is its capacity in reducing post-operative infections.

Along with the mentioned prospective studies, a short note on the influence of IV antibiotics during third molar surgery was described by Martin et al. ${ }^{2}$ They emphasized the importance of dosage timing and its potency in reducing post-surgical infections. The authors also described other associated perspectives such as systemic after effects and economic factors, which restrict parenteral antibiotic use among general dentists. ${ }^{2}$ Besides, a chronicle advocate's the use of parenteral antibiotics in osteotomy and since the authors discussed mainly the pharmacologic strategies in reducing post-operative pain, swelling and trismus after third molar 
Table 1: Summary of peer-reviewed articles.

\begin{tabular}{|c|c|c|c|c|}
\hline Author & Design of study & Number of subjects & $\begin{array}{l}\text { Dose of Intravenous } \\
\text { Antibiotics }\end{array}$ & Inference \\
\hline \multirow[t]{2}{*}{ Foy et al..$^{30}$} & \multirow[t]{2}{*}{ Prospective } & Control group: 60 & No antibiotics & $\begin{array}{l}\text { High risk patients, susceptible to } \\
\text { complications benefit with intravenous } \\
\text { antibiotics }\end{array}$ \\
\hline & & Experimental group: 56 & $\begin{array}{l}\text { Ampicillin (1g IV) or } \\
\text { Clindamycin (300mg IV for } \\
\text { penicillin-allergic subjects) }\end{array}$ & \\
\hline \multirow[t]{2}{*}{ Halperan and Dodson ${ }^{31}$} & \multirow[t]{2}{*}{$\begin{array}{l}\text { Placebo-controlled, } \\
\text { double-blind, } \\
\text { randomized clinical } \\
\text { trial }\end{array}$} & Control group: 59 & $\begin{array}{l}\text { Penicillin }(15,000 \mathrm{units} / \mathrm{kg} \text { IV }) \\
\text { or Clindamycin ( } 600 \mathrm{mg} \text { IV for } \\
\text { penicillin-allergic subjects). }\end{array}$ & \multirow[t]{2}{*}{$\begin{array}{l}\text { IV antibiotics reduce the surgical site } \\
\text { infections. }\end{array}$} \\
\hline & & Experimental group :59 & CG: $0.9 \%$ saline solution & \\
\hline Martin et al. ${ }^{2}$ & Commentary report & - & - & $\begin{array}{l}\text { Emphasize the importance in parenteral } \\
\text { dosage timing and its potency in reducing } \\
\text { post-surgical infections. }\end{array}$ \\
\hline $\begin{array}{l}\text { Francesco Sortino and } \\
\text { Marco } \text { Cicciù }^{33}\end{array}$ & Narrative review & - & - & $\begin{array}{l}\text { Parenteral antibiotic prophylaxis } \\
\text { recommended only in ostetotomy subjects. }\end{array}$ \\
\hline \multirow[t]{3}{*}{ Susarla et al. ${ }^{34}$} & \multirow[t]{3}{*}{ Systematic review } & Systematic Review-1; & - & \multirow{3}{*}{$\begin{array}{l}\text { Single dose of IV antibiotic (Peniciilin/ } \\
\text { Clindamycin) reduce } \\
\text { post-operative infections. }\end{array}$} \\
\hline & & $\begin{array}{l}\text { Randomized controlled } \\
\text { clinical trials-12 (Among 12, } \\
\text { one study interprets the IV } \\
\text { application) }\end{array}$ & & \\
\hline & & 2396 subjects & & \\
\hline \multirow{3}{*}{$\begin{array}{l}\text { William Caetano } \\
\text { Rodrigues et al. } .^{35}\end{array}$} & \multirow[t]{3}{*}{ Systematic review } & Systematic Reviews- 8; & - & \multirow{3}{*}{$\begin{array}{l}\text { The review outcomes suggest both (oral } \\
\text { and IV) routes of antibiotic practice as } \\
\text { inessential for healthy candidates and } \\
\text { preferably advocate IV application in } \\
\text { geriatricl neglected health candidates and } \\
\text { gastrointestinal disorders. }\end{array}$} \\
\hline & & $\begin{array}{l}\text { Randomized controlled } \\
\text { clinical trials- } 20\end{array}$ & & \\
\hline & & $\begin{array}{l}\text { (Parenteral route was } \\
\text { preferred only in } 4 \text { studies) }\end{array}$ & & \\
\hline
\end{tabular}

surgery, much detail were not found regarding to the application of intravenous antibiotics. ${ }^{33}$ Susarla et al. published an evidence ba sed review assessing the effect of antibiotics in reducing post-operative surgical site infections (SSI). ${ }^{34}$ Around 12 randomized clinical trials and a systematic review were finally considered from 114 titles, including the hallmark paper on IV by Halpern et al. ${ }^{31}$ The extreme standards maintained in the retrieval of literature and the meticulous comparison of results further strengthens the study. The authors affirmed that the administration of antibiotics compliments the treatment rather than causing any threat. As an additional note, they also supported the practice of pre-operative single dose IV (penicillin /clindamycin) antibiotic in preventing SSI. ${ }^{34}$

Despite these reports, there is no compilation of positive data pertinent to IV antibiotics in the literature. Fortunately, an exhaustive report addressed by Rodrigues et al. does not leave a large gap in the literature. ${ }^{35}$ The authors aimed to propose the absolute indications of antibiotics during third molar surgery after analyzing the recent scientific evidence. Their extensive report addresses most of the antibiotic administration routs including oral, intramuscular, intravenous and topical application. The oral route showed the highest preference among the considered studies, for the reason that intravenous route is not cost-effective and invasive on par with the other modalities. This negative response raises a question- are we ethical towards the community or at least successful in reducing the infection rates? However, the investigating team specified the conditions justifying administration of IV antibiotics. The review suggests both (oral and IV) routes of antibiotic practice as nonessential for healthy candidates, but preferably advocates IV application in geriatric or neglected health candidates and gastrointestinal (GIT) disorders. ${ }^{35}$
Furthermore, the survey also mentions the appropriate antibiotics to consider, when the chosen path is IV. As stated earlier, the investigators proposed amoxycillin and penicillin as the first line of drugs, followed by clindamycin, azithromycin and metronidazole. Even though an exclusive review was missing during the literature search, recent literature portrayed the indications of IV antibiotics during third molar surgery in a nutshell. Being a short note (letter to editor), it is not adequate in delivering an in-depth discussion to the readers. ${ }^{36}$

The parenteral drugs are rapidly absorbed in blood, whereas those given via oral route are encountered with gastrointestinal enzymes that may reduce their bio-availability. Benefits of IV antibiotics are high, as adequate concentration in tissue can be attained in a short time. The broadspectrum antibiotics work against a wide range of micro-flora in controlling the spread of infection. Therefore, they remain the mainstay for odontogenic infections in dentistry, but their associated side effects such as thrombosis phlebitis and urticaria warn us to prescribe with optimum dosage. Administration rate and dosage timing are in the hand of operator, as injecting IV drugs at a slow rate can considerably minimize the known side effects. Adverse drug reactions could result from all drugs and are severe compared to side effects. Pharmacological citations affirm that antibiotic adverse events (GIT disturbances) are of first order in occurrence affecting more geriatric and immune compromised subjects. ${ }^{37-39}$ Although, contemplating the present scenario, proper strategies in choosing the right drug, right dosage and right timing can prevent the speculated unfavorable consequences (antibiotic associated diarrohea, hypertrophy of fungal strains). On a general note, the majority of the antibiotic adverse reactions are avoidable. ${ }^{39}$ An honest interaction 
with patients during initial visit and tendency to analyze the etiology can avert the harmful reactions.

If one has to substantiate IV antibiotics in terms of advantage, their dosage aspects dominate the other route of administrations. The analyzed prospective studies strongly recommend the practice of single IV dose to be much competent than multiple dosing. ${ }^{31,32}$ Furthermore, as the stated trials undertook systematized measures, the single dose regimen one hour prior to the surgery is still considered as golden rule in IV dictionary. As such, there are no contraindications in IV antibiotics, unless the practitioner feels that present situation demands an oral route. Other deciding factors in IV antibiotics are the expenditure, sterilization, professional skill and associated bacteremia. When one looks at the economical aspect, the cost factors do escalate compared to oral drugs, which is still a setback in low income countries. Secondly, the frequency of complications is related with professional experience. ${ }^{40,41}$ Oral-maxillofacial surgeons are equally responsible for the potential risk of complications, despite their proficiency. There are mixed statements in the literature regarding the competency of oral experts and general dentists for third molar surgery. ${ }^{40-43}$ Further conclusive comments depend on the future studies considering a large population and other parameters. On ethical perspective when the work pressure exceeds a dentist's capacity in performing the surgical technique safely, referring to experts is a safe and healthy protocol. In order to ensure patient's well-being, performing under the guidance of a medical specialist could allay adverse effects. In context of oral infections, invasive procedures may induce bacteremia as the risk is pronounced. Considering the individuals whom suffer from compromised $\backslash$ neglected health could be victims of post-operative bacteremia which in turn could lead to inflation in the frequency of such infections. The current investigation confirms increased chances of bacterial infection following surgical removal of third molar. ${ }^{44}$ However, the prognosis of bacteremia depends on the trauma and the contamination at surgical site and time consumed. The execution of surgical procedure within a short period benefits IV administration and enhances drug potential. On that account, surgical duration is another vital element to be considered by a dentist. Even though, the present results did not yield a meta-analysis report during screening, the authors believe that use of the IV antibiotics would increase considering the rapid absorption of parenteral drugs in blood. The authors re-state that the current article does not address the topic of whether intravenous antibiotics should be used for all third molar removals, rather the mechanism and most importantly the timing of administration in the setting they are used.

\section{Interventions}

IV drug administration being a vital process of cure in general surgery has been of considerable interest among physicians and researchers. Dental surgeons, assistants, nurses and practitioners need guidance and evaluation of their skills by undergoing certified training program. Theoretical and practical components should be mutually assessed to develop and improvise the professional skill.

\section{Scope: Present and Future}

Reputed organizations, notably AAOMS and AAPD, have been involved in formulating clinical guidelines for pediatric and elderly patients to enhance the surgical (oral) procedures. ${ }^{45,46}$ The comprehensive documents are revised periodically and updated to meet the current requirements. An extensive project on third molar clinical trials, supported by AAOMS, Oral/Maxillofacial Surgery Foundation (OMSF) and Oral/ Maxillofacial Surgery grants (University of Kentucky and University of North Carolina) was carried out for five years to evaluate the outcomes during conservation and extraction of third molar tooth. ${ }^{46}$ The investigation team made sincere efforts in encompassing most of the associated variables, risk factors and hypotheses for the management of third molar surgery. They serve as core documents and there have been published more than 120 articles so far, based on Third Molar Clinical Trials. The data greatly serve as a surgical manual for the current generation of dentists and will also be helpful in future. The pharmacologic perspectives are also included in the final version. The information included in the summary part highlights the utility of IV antibiotic to accelerate clinical recovery. ${ }^{47}$ The recent researches do suggest need for randomized clinical trials in order to produce convincing evidence on antibiotic prophylaxis during oral surgical maneuvers. ${ }^{48}$ In upcoming years, the inclusion of longitudinal studies and parameters regarding pharmacological interventions, drug dosages and interactions could be promising for the budding health-care professionals. In association with the blooming growth in pharma-care industry and improved protocols, we can expect more pharmacists, pharmacologists and clinicians to pay attention towards IV drug applications in multifarious dental disciplines.

\section{Clinical Significance}

The present review is first of its kind reporting an in-depth discussion on the historical journey of intravenous antibiotics and eventually hopes to serve as a pharmacological manual to oral health-care professionals and enable them to reap the benefits of IV antibiotics during dento-alveolar surgery.

\section{Limitations}

The purpose of the present review was to highlight the relation between IV antibiotics and third molar surgery. However, further investigations and discussions are required regarding its application in different dentoalveolar procedures such as pre-prosthetic surgery, bone grafting and installation of (dental) implants.

\section{CONCLUSION}

It reminds me an old adage "Know your enemy and win the war". In a similar vein, the outcome of the proposed treatment depends on the prevailing health system and intensity of oral infections. From the retrieved evidences, it can be asserted that candidates with clinical signs of rapid progressive infection, total osseous impaction and compromised health deserve to receive a pre-operative single dose of IV antibiotics during third molar surgery on the grounds of their vulnerability to bacteremia. The pre-operative planning proportionally serves to enhance the prognosis of dento-alveolar surgery. On the other hand, the misuse of antibiotics leads to anti-microbial resistance and deteriorate the existing medical status. However, the final decision depends on the operator and potential risk factors need to be taken into account prior choosing the prophylaxis. The preferred route and antibiotics should outweigh the underlying complications to serve as an efficient channel in reducing postoperative infections. IV antibiotics should be used as adjuvants with surgical procedure rather than the primary mode of treatment. A right drug when given at right time with right dosage yields favorable results. In summary, even though literature is not well-grounded with high quality clinical trials and overviews, it can be concluded that the peak plasma concentrations of an antibiotic after IV administration are suggestive of its high efficiency compared to oral route.

\section{ACKNOWLEDGEMENT}

I gratefully acknowledge the financial support received from Research Management Centre, AIMST University, Malaysia.

\section{CONFLICT OF INTEREST}

The authors declare no conflict of interest.

\section{ABBREVIATIONS}

AAOMS: American Association of Oral Maxillofacial Surgeons; AAPD: American Academic of Pediatric Dentistry; OMSF: Oral/Maxillofacial 
Surgery Foundation; IV-Intravenous; IM: Intramuscular; SC: Subcutaneous; SSI- Surgical Site Infection; GIT: Gastrointestinal.

\section{REFERENCES}

1. Carlos AA, Mário SS, Marcelo MR, Talita GC, Roberta MS, Fernanda PA. Clinical and surgical evaluation of the indication of postoperative antibiotic prescription in third molar surgery. Oral Surg, Oral Med, Oral Pathol, Oral Radiol. 2012;114(5):S26-S31.

2. Martin MV, Kanatas AN, Hardy P. Antibiotic prophylaxis and third molar surgery. Br Dent J. 2005;198(6):327-30

3. Vlcek D, Razavi A, Kuttenberger JJ. Antibiotics in third molar surgery. Swiss Dent J. 2014;124(3):294-302.

4. Friedman JW. The prophylactic extraction of third molars: A public health hazard. Am J Public Health. 2007;97(9):1554-9.

5. John HC. Pathology associated with the third molar. Oral Maxillofacial Surg Clin N Am. 2013;25(1):1-10

6. Al-Anqudi SM, Al-Sudairy S, Al-Hosni A, Al-Maniri A. Prevalence and pattern of third molar impaction: A retrospective study of radiographs in Oman Sultan. Qaboos Univ Med J. 2013;14(3):388-92.

7. Khawaja NA, Khalil H, Parveen K, Al-Mutiri A, Al-Mutiri S, Al-Saawi A. A retrospective radiographic survey of pathology associated with impacted third molars among patients seen in oral and maxillofacial surgery clinic of college of dentistry, Riyadh. J Int Oral Health. 2015;7(4):13-7.

8. Santosh P. Impacted mandibular third molars: Review of literature and a proposal of a combined clinical and radiological classification. Ann Med Health Sci Res. 2015;5(4):229-34.

9. Anand SK, Kumar GR, Shruthi BS, Supriya AN. Pericoronal radioluciencies with significant pathology: Clinico-histopathologic evaluation. Biomed J. 2015;38(2):141-52

10. Sara M, El-Khateeb, Eman AA, Tamer H. Radiographic assessment of impacted teeth and associated pathosis prevalence. Saudi Med J. 2015;36(8):973-9.

11. David N. Third molars: To extract or not to extract?. Dental Press J Orthod. 2015;20(4), 17-8

12. Goyal S, Verma P, Raj SS. Radiographic evaluation of the status of third molars in Sriganganagar population- a digital panoramic study. Malay $\mathrm{J}$ of Med Sci. 2016;23(6):103-12

13. Figueiredo R, Valmaseda-Castellón E, Formoso-Senande F, Berini-Aytés L, GayEscoda C. Delayed-onset infections after impacted lower third molar extraction: Involved bacteria and sensitivity profiles to commonly used antibiotics. Ora Surg, Oral Med, Oral Pathol, Oral Radiol. 2012;114(1):43-8.

14. Bryce D, Leavitt JM, Van E. Rapid early-onset group A streptococcus infection after impacted third molar removal: A review and case series. J Oral Maxillofac Surg. 2012;70(12):2742-7.

15. Baddour LM, Epstein AE, Erickson CC, Knight BP, Levison ME, Lockhart PB, et al. A summary of the update on cardio-vascular implantable electronic device infections and their management: A scientific statement from the American heart association. J Am Dent Assoc. 2011:142(2):159-65.

16. Ramasamy C. A cautionary tale on the central venous catheter: Medical manual for oral physicians. Malay J Med Sci. 2015;22(5):76-84

17. Ramasamy $\mathrm{C}$. Should a dentist be alarmed while managing breast augmented patient?. Dent Hypotheses. 2015;6(1):34-5.

18. Thomas PS, Elliot A, Peter BL, Edmond T, Thomas MP, Sharon LT, et al. The use of prophylactic antibiotics prior to dental procedures in patients with prosthetic joints. J Am Dent Assoc. 2015;146(1):11-6.

19. Ramasamy C. Dentist-Urologist interplay in the dental management of penile prosthesis patient. J Coll Physicians Surg Pak. 2015;25(8):628.

20. Ramasamy C. Dentist-Nephrologist symbiosis in the dental management of chronic kidney disease patient. J Coll Physicians Surg Pak. 2015;24(12):95.

21. Ramasamy C. Optimal antibiotic dosage for chronic kidney disease patient in dental office: Pharmacological manual for oral clinicians. Recent Pat Antiinfect Drug Discov. 2015;10(2):113-23.

22. Ramu C, Padmanabhan TV. Indications of antibiotic prophylaxis in dental practice. Asian Pac J Trop Biomed. 2012;2(9):749-54.

23. Ramasamy $\mathrm{C}$. Final thoughts on antibiotic use: wake up call for the oral health care professionals. Asian Pac J Trop Biomed. 2014;4(suppl 2):s562-7.

24. Fernandes MJ, Ogden GR, Pitts NB, Ogston SA, Ruta DA. Actuarial life-table analysis of lower impacted wisdom teeth in general dental practice. Community Dent Oral Epidemiol. 2010;38(1):58-67.

25. Dodson TB. Surveillance as a management strategy for retained third molars: Is it desirable?. J Oral Maxillofac Surg. 2012;70(9):S20-4.
26. Bouloux GF, Busaidy KF, Beirne OR, Chuang SK, Dodson TB. What is the risk of future extraction of asymptomatic third molars? a systematic review. Oral Maxillofac Surg Clin North Am. 2015;27:363-71.

27. Irja V. How often do asymptomatic, disease-free third molars need to be removed?. J Oral Maxillofac Surg. 2012;70(9 Suppl 1):S41-7.

28. Louis KR. Removal of asymptomatic third molars: A supporting view. J Oral Maxillofac Surg. 2006;64(12):1811-5

29. Martin BS. The indications for third-molar extractions. J Am Dent Assoc. 2014; 145(6):570-3

30. Foy SP, Shugars DA, Phillips C, Marciani RD, Conrad, SM, White RPJ. The impact of intravenous antibiotics on health-related quality of life outcomes and clinical recovery after third molar surgery. J Oral Maxillofac Surg. 2004;62(1):1521.

31. Halpern LR, Dodson TB. Does prophylactic administration of systemic antibiotics prevent postoperative inflammatory complications after third molar surgery?. J Oral Maxillofac Surg. 2007;65(2):177-85.

32. Itzhak B, Mike AOL, George KS, Marjorie J, Samaranayake LP, Jorge VR. Clindamycin in dentistry: more than just effective prophylaxis for endocarditis? Oral Surg, Oral Med, Oral Pathol, Oral Radiol, Endod. 2005;100(5):550-8.

33. Francesco S, Marco C. Strategies used to inhibit postoperative swelling following removal of impacted lower third molar. Dent Res J. 2011;8(4):162-71.

34. Srinivas MS, Basel S, Thomas BD. Do antibiotics reduce the frequency of surgical site infections after impacted mandibular third molar surgery?. Oral Maxillofacial Surg Clin N Am. 2011;23(4):541-6.

35. Willian CR, Roberta O, Eduardo PP, Anjos DC, Rafael SDA, Willian MDM. Antibiotic prophylaxis for third molar extraction in healthy patients: current scientific evidence. Quintessence Int. 2015;46(2):149-61.

36. Ramasamy C, Jawahar D. Intravenous antibiotic: Potential alternative for restricted oral route during removal of third molar. J Young Pharm. 2016;8(1):59.

37. Davies EA, Mahony MSO. Adverse drug reactions in special populations-the elderly. Br J Clin Pharmacol. 2015:80(4):796-807.

38. Muaed JA. Factors affecting the development of adverse drug reactions. Saudi Pharm J. 2014;22(2):83-94.

39. Wawruch M, Bozekova L, Krcmery S, Kriska M. Risks of antibiotic treatment Bratisl Lek Listy. 2002;103(7/8):270-5.

40. Lee CT, Zhang S, Leung YY, Li SK, Tsang CC, Chu CH. Patients' satisfaction and prevalence of complications on surgical extraction of third molar. Patient Prefer Adherence. 2015;9:257-63.

41. Jerjes W, Upile T, Nhembe F, Gudka D, Shah P, Abbas S, et al. Experience in third molar surgery: an update. Br Dent J. 2010;209(1):E1.

42. Adriana MC, Daniel TB, Fernando PMG, Paulo ZG, Eduardo S, Thiago JD, et al. Are antibiotics necessary after lower third molar removal?. Oral Surg, Oral Med Oral Pathol, Oral Radiol. 2012;114(5):S199-208.

43. MAievic M, Uzarevic Z, Gvozdic V, Mikelic VM, Leovic D, Macan D. The influence of surgical experience, type of instructions given to patients and patient sex on post-operative painintensity following lower wisdom tooth surgery. Acta Clin Croat. 2013;52(1):23-8.

44. Mang-De LRMR, Castellanos-Cosano L, Romero-Perez MJ, Cutando A. The bacteremia of dental origin and its implications in the appearance of bacterial endocarditis. Med Oral Patol Oral Cir. Bucal. 2014;19(1):67-73.

45. American Association of Oral and Maxillofacial Surgeons. Parameters of care: clinical practice guidelines for oral and maxillofacial surgery (AAOMS Par Care 12, Ver 5). J Oral Maxillofac Surg. 2012;70:61-4.

46. American Academic of Pediatric Dentistry. Guideline on antibiotic prophylaxis for dental patients at risk for infection. Reference Manual. 2014;36:287-92.

47. Banks KA, Beirne OR, Busaidy KF, Eisig SB, Larsen PE, White RPJ. Summary of the third molar clinical trials: report of the AAOMS task force for third molar summary. Special contribution. J Oral Maxillofac Surg. 2012;70(9):2238-48.

48. Kilian K, Katharina S, Jochen W. Current evidence regarding prophylactic antibiotics in head and neck and maxillofacial surgery. Bio Med Research International. 2014;2014. Article ID 879437. 